\title{
Diversity and Demographics of Zooarchaeologists: Results from a Digital Survey
}

Suzanne E. Pilaar Birch

Author Address: Department of Anthropology, University of Georgia, 250 Baldwin Hall, Jackson Street, Athens, GA 30602, USA.

Email: sepbirch@uga.edu

Received: September 10, 2015

Volume: 6(2):276-284

Published: December 18, 2015

(C) 2015 Society of Ethnobiology

Abstract: Nearly 25 years ago, a "Zooarchaeology Practitioner Survey" was distributed via conventional mail to individuals in the USA and Canada and received 122 responses over a period of several months in 1991. Now, a revised "Demographics in Zooarchaeology Survey" provides an update to those data and assesses the current state of the field. The 2014 survey remained open for 3 months and received 288 responses from practitioners worldwide. Global participation was made possible by hosting the survey online. Key findings of the 1991 survey included disparities in employment rank for women despite similar levels of degree level attainment as men, a point which the 2014 survey sought to investigate. This trend appears to persist for those without the PhD and at the highest levels of income for those holding a PhD. In addition, the recent survey asked participants about their racial or ethnic identity in order to evaluate the demographic diversity of the discipline beyond sex, age, and nationality. Data regarding topical and geographic research area were also collected and reflect a subtle bias towards working with mammals and a focus on research questions grounded in prehistory in Europe and North America, followed by Australia and Southwest Asia. Results are compared with those of the earlier survey and membership information from the International Council for Archaeozoology.

Keywords: Demographics, Archaeology, Diversity, Gender, Zooarchaeology

\section{Introduction}

As specialists in the study of human-animal relationships in the past, zooarchaeologists are often concerned with determining the diversity of animal taxa, reconstructing population demographics, and evaluating species richness. This paper turns those concepts around on zooarchaeologists themselves, discussing the diversity and demographics (and yes, even "richness") of those who identify as part of this community. The study was motivated by the nearly 25 year-old "Zooarchaeology Practitioner Survey," which was mailed to individuals in the USA and Canada in 1991 and received approximately 122 responses over a period of several months. (GiffordGonzalez, 1993, 1994). During the 1980s and early 1990s in the US, it was generally perceived that fewer women than men were professional archaeologists and that women who did work in archaeology tended to hold more laboratory and specialist positions, an assumption that carried a negative connotation (Gero 1985, Gifford-Gonzalez 1994). In Gifford-Gonzalez's 1991 survey, multiple respondents took the opportunity in the comments section to wonder whether there were more women than men in the field of zooarchaeology - aka "bone people." In fact, 50\% of respondents to the initial survey-drawn from the subscribership pool of Zooarchaeology Research News, ${ }^{1}$ which included students and non-professionals-were women. The American Anthropological Association Anthro Guide, ${ }^{2}$ in contrast, listed all active anthropology departments, their faculty members, and other professional members of the American Anthropological Association. Thus, the Anthro Guide told a different story: only $36 \%$ of zooarchaeologists were women, a figure that Gifford-Gonzalez noted reflected the same relative proportion of female archaeology $\mathrm{PhDs}$ for the previous decade. These figures represent a 'gap' of roughly $15 \%$ between degree attainment and professional status for women in zooarchaeology in the US and Canada in the 1990s. When compared against the current AnthroGuide numbers, 48\% of listed zooarchaeologists are men, while $52 \%$ are women $(n=126)$ (American Anthropological Association 2015).

For archaeology in general, by the mid-1990s, a survey conducted for the Society for American 
Table 1. Distribution of zooarchaeologists by continent and country showing the number of survey respondents and 2014 ICAZ members.

\begin{tabular}{|c|c|c|c|c|c|}
\hline Region & Survey & ICAZ & Region & Survey & ICAZ \\
\hline Africa & 4 & 12 & Europe & 128 & 207 \\
\hline Botswana & 0 & 1 & Austria & 4 & 1 \\
\hline Egypt & 1 & 2 & Belgium & 4 & 4 \\
\hline \multirow[t]{2}{*}{ South Africa } & 3 & 9 & Bulgaria & 0 & 1 \\
\hline & & & Cyprus & 0 & 1 \\
\hline Asia & 6 & 45 & Czech Republic & 0 & 2 \\
\hline Armenia & 1 & 1 & Denmark & 2 & 7 \\
\hline China & 0 & 8 & Estonia & 0 & 1 \\
\hline India & 0 & 8 & Finland & 1 & 1 \\
\hline Iran & 0 & 3 & France & 12 & 34 \\
\hline Israel & 1 & 5 & Germany & 8 & 20 \\
\hline Japan & 0 & 7 & Greece & 5 & 1 \\
\hline Lebanon & 0 & 1 & Hungary & 1 & 4 \\
\hline Republic of Korea & 1 & 4 & Iceland & 1 & 0 \\
\hline Russia & 2 & 4 & Ireland & 1 & 3 \\
\hline Sri Lanka & 0 & 1 & Italy & 2 & 10 \\
\hline \multirow[t]{2}{*}{ Turkey } & 1 & 3 & Netherlands & 1 & 7 \\
\hline & & & Norway & 2 & 1 \\
\hline North America & 100 & 195 & Poland & 1 & 5 \\
\hline Canada & 16 & 29 & Portugal & 5 & 3 \\
\hline Mexico & 0 & 9 & Romania & 2 & 3 \\
\hline Panama & 0 & 2 & Serbia & 2 & 4 \\
\hline Puerto Rico & 0 & 1 & Spain & 4 & 16 \\
\hline \multirow[t]{2}{*}{ United States } & 84 & 154 & Sweden & 5 & 3 \\
\hline & & & Switzerland & 3 & 8 \\
\hline South America & 13 & 81 & United Kingdom & 62 & 67 \\
\hline Argentina & 10 & 55 & & & \\
\hline Bolivia & 0 & 5 & Other & & \\
\hline Brazil & 2 & 3 & Multiple Countries & 3 & \\
\hline Chile & 0 & 9 & No Response & 15 & \\
\hline Colombia & 1 & 5 & & & \\
\hline Peru & 0 & 4 & & & \\
\hline Australia \& Oceania & 19 & 29 & & & \\
\hline Australia & 16 & 21 & & & \\
\hline New Zealand & 3 & 8 & & & \\
\hline
\end{tabular}

Archaeology (SAA) showed that while slightly more than $50 \%$ of graduate students in archaeology were female $(n=250)$, that number dropped to around $35 \%$ in the category of professional $(n=1634)$ with a significant trend towards more women in younger age cohorts (Zeder 1997) revealing a similar 15\% gap in the transition from student to professional for women in archaeology. Ten years later, a 2004 salary survey by the SAA showed that these numbers had shifted only slightly, with $40 \%$ of professionals identifying as female ( $\mathrm{n}=2143$ ) (Association Research 2005) and continued disparities in career advancement and income levels for women. According to the National Science Foundation (2015), from 2006 to 2012, the proportion of women completing a $\mathrm{PhD}$ in anthropology (including archaeology) in the United States increased by just over $10 \%$ (from $53 \%$ to $64 \%, n=625$ in 2012). This trend of growth beginning in the 


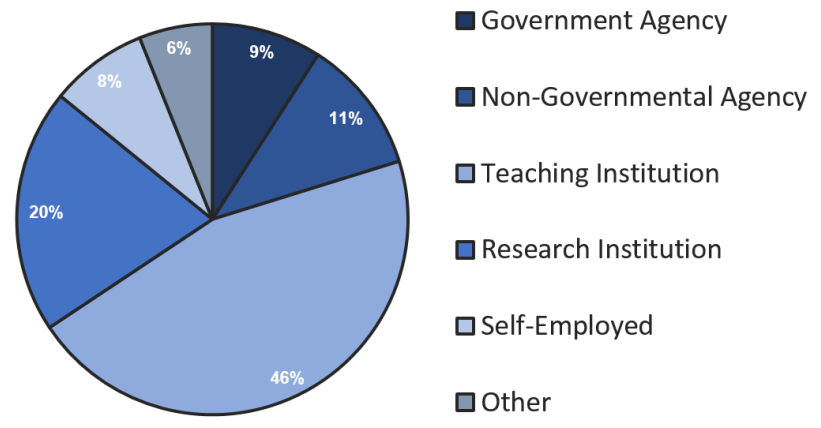

Figure 1. Distribution of work placement $(n=288)$.

1990s — and in some cases, a growing majority in the 2000s - has also been noted in the UK (Aitchison and Rocks-Macqueen 2013) and Europe (Lazar et al. 2014) but not Australia (Ulm et al. 2005). As of December 2014, membership of the International Council for Archaeozoology (ICAZ) included both students and professionals, and stood at about $60 \%$ women. How are broader temporal and field-wide trends in education and employment reflected in the makeup of practicing zooarchaeologists? To address these questions, I designed and circulated an online survey in early 2014, which remained open for 3 months. The survey received 288 responses from practitioners worldwide, including large numbers of responses from the United States and Canada. This enabled detailed assessment and comparison with the 1991 survey data for these countries of these disciplinary settings.

Based on the findings and interpretations of Gifford-Gonzalez $(1993$, 1994) the primary purpose of this updated survey was to assess the current numbers of women in the field, their educational attainment level, their rank, and their career satisfac- tion. Responses were evaluated in relation to those expected based on earlier surveys and membership records as noted above, thereby providing a 23-year window into zooarchaeological demographics. In particular, this survey sought to investigate the previous finding that women had equal levels of education to men but did not hold an equal percentage of professional or senior positions, and therefore, that women earned less despite having a similar educational attainment level. However, interesting patterns also emerged in the comments section regarding job satisfaction and in evaluating racial and ethnic self-identification as well as attitudes towards this question.

\section{Methods}

For this survey, the widespread use and availability of the internet and online data collection allowed for global participation. The survey was distributed using professional email listservs, websites, and social media outlets such as Twitter and Facebook. Respondents completed one anonymous online survey via Google Forms, comprised of 20 questions. Due to the anonymous nature of responses, an Institutional Review Board exemption was granted by the Brown University Research Protections Office (\#1309000919). A number of survey fields allowed for anecdotal responses or comments. Following the survey period, data were tabulated and the results analyzed as percentages. The survey instrument is available as a supplementary file and can be accessed online on BoneCommons

(http://www.alexandriaarchive.org/bonecommons/ items/show/1986).

Participants agreed to a statement of consent that made clear that individual anonymous comments

Table 2. Geographical expertise for all respondents as well as those in the US \& Canada.

\begin{tabular}{lrrrr}
\hline $\begin{array}{l}\text { Regional } \\
\text { Expertise }\end{array}$ & $\begin{array}{r}\text { First Choice } \\
\text { All }\end{array}$ & $\begin{array}{r}\text { First Choice } \\
\text { US \& Canada }\end{array}$ & $\begin{array}{r}\text { Second Choice } \\
\text { All }\end{array}$ & $\begin{array}{r}\text { Second Choice } \\
\text { US \& Canada }\end{array}$ \\
\hline Africa & 7 & 2 & 8 & 3 \\
Australia & 45 & 0 & 1 & 0 \\
Central Asia & 0 & 0 & 3 & 0 \\
Europe & 108 & 7 & 38 & 19 \\
Mesoamerica & 4 & 3 & 4 & 4 \\
North America & 77 & 66 & 0 & 0 \\
Oceania & 10 & 1 & 2 & 3 \\
South America & 13 & 0 & 5 & 2 \\
South Asia & 0 & 0 & 3 & 1 \\
Southeast Asia & 2 & 0 & 9 & 3 \\
Southwest Asia & 40 & 17 & 5 & 5 \\
Other & 5 & 3 & 5 & \\
\hline
\end{tabular}




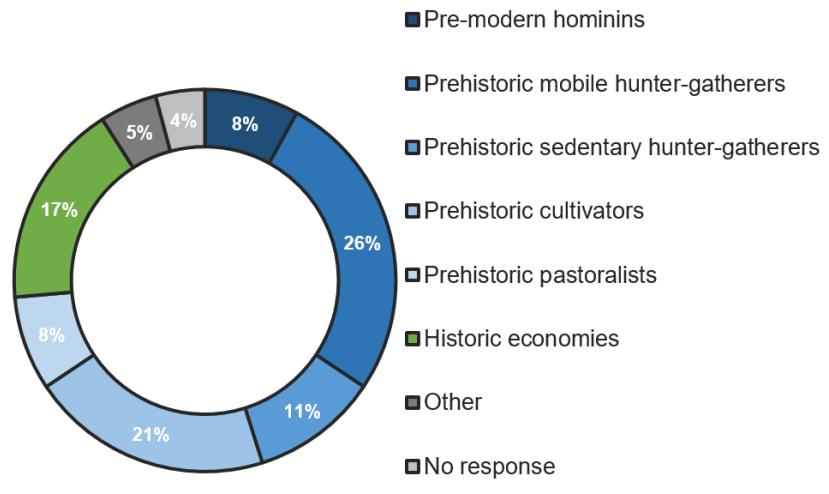

Figure 2. Research topics among zooarchaeologist $(n=288)$, predominantly focused on prehistory.

might be included in final publication of the survey. The survey was published in English only with the option to use Google Translate and targeted a global, professional audience (18 years and older). Many of the survey questions derived directly from GiffordGonzalez's 1991 survey (Gifford-Gonzalez pers. comm.) to allow for comparison of the results and the potential identification of long-term trends.

\section{Results}

\section{Respondents}

Overall, a majority of the 288 survey respondents $(57 \%)$ are women; this represents a shift from the 1991 results, which had a nearly equal number of responses from both men and women. The ratio of women to men in the sample closely resembled that of the membership in ICAZ $(60 \%, n=563)$, although current membership status of respondents as of 2014 was not ascertained as part of the survey. In the US and Canada, $61 \%$ of the respondents were women $(\mathrm{n}=100)$. Participants hailed from 35 countries across 6 continents (Table 1). The geographic distribution of respondents appears to be more representative for some regions than others; for example, while 62 survey participants listed their country of residence as the UK compared to $67 \mathrm{UK}$ ICAZ members, some countries such as Mexico (with 9 ICAZ members) are not represented in the survey. Not all respondents gave a reply for each question.

\section{Work Placement and Research Focus}

Based on survey responses, nearly half of zooarchaeological practitioners are based in higher learning institutions $(45 \%)$, followed by research institutions such as museums (20\%) (Figure 1). Approximately $11 \%$ work in non-governmental agencies (including cultural resource management firms) and $9 \%$ in government agencies. Around $8 \%$ are self-employed, usually characterized as "freelance consulting" in the comments section. Finally, a small number of respondents $(6 \%)$ were either retired, hobbyists, or no longer pursuing zooarchaeology as a major career focus. The scenario is similar for the US and Canada, with the most notable difference between research and teaching institutions; education made up $56 \%$ of work placement and research institutions only 13\% $(n=100)$. In addition, participants were queried as to whether their zooarchaeological employment was full time, part time, or intermittent. Based on the US and Canadian sample, about $27 \%$ of respondents carried out zooarchaeological work full-time, $29 \%$ part-time, and $44 \%$ intermittently (including field season and periodic work; $n=97$ ). Of those, about $80 \%$ of full time and $60 \%$ of part time zooarchaeologists were women, while the intermittent category was evenly split. This suggests that a higher proportion of women are based in technician or research-only positions that tend to dedicate more time to faunal analysis but are also associated with lower pay rates and perceived status.

The survey also documents trends in the geographical distribution of zooarchaeological research, including certain regions that have traditionally received more attention than others (Table 2). For example, a majority of analyses focus on faunal material derived from sites in Europe and North America and are carried out by researchers based in those regions, followed by Australia and Southwest Asia. Central Asia, South and Southeast Asia, and the African continent as a whole are less well represented.

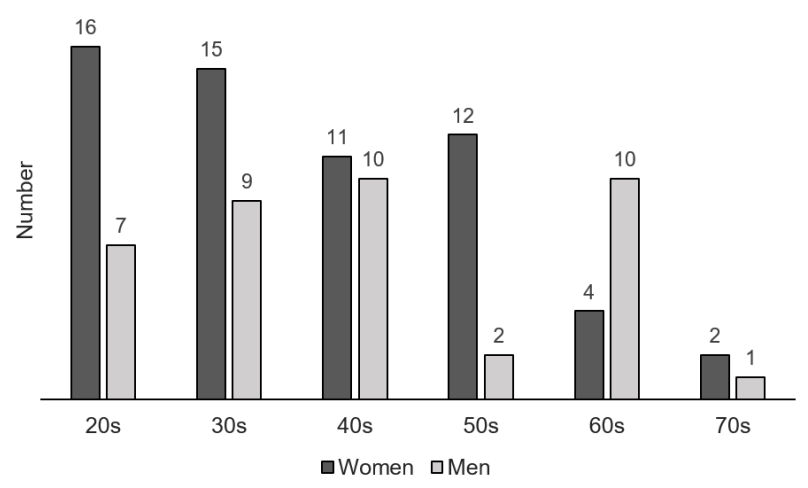

Figure 3. Age of survey respondents in the US and Canada. 


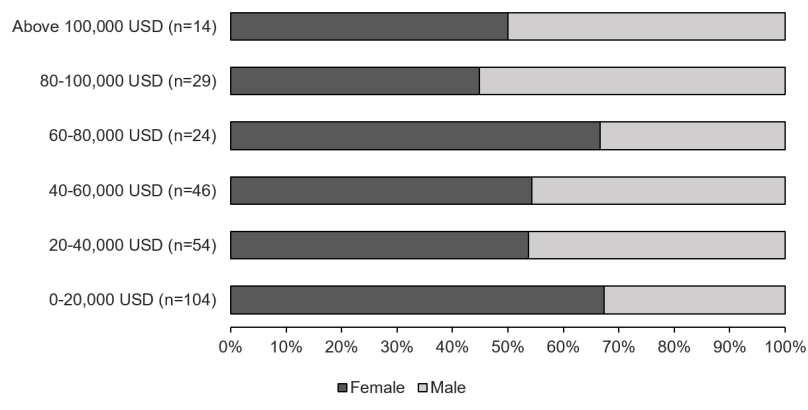

Figure 4. Percentage of men and women within each income bracket $(n=271)$.

Topical research areas followed categories set out in Gifford-Gonzalez's 1991 question. The study of prehistoric mobile hunter-gatherers was the most common topical area of research focus among respondents, followed by prehistoric cultivators, historic economies, and then prehistoric sedentary hunter-gatherers; most zooarchaeologists work in prehistory (Figure 2). Some of the responses in the category of 'other' included those working on skeletal morphology, paleobiology, systematics, breeds, and pathology. There were no significant differences in research topics between women and men.

Survey respondents indicated that their analyses tend to focus on either mammals $(50 \%)$ or a combination of mammals, birds, fish, and molluscs (40\%), with small numbers specializing in each alternative category listed. This stands in contrast to GiffordGonzalez's earlier results, in which about $50 \%$ of respondents worked with combinations of animal classes and only $40 \%$ on mammals; there are less people working primarily on fish remains $3 \%$ from $6 \%$ ) and more on birds (2\%) and molluscs (3\%) (from $1 \%)$. It did not appear that men or women tended to specialize more in any given taxa.

Degree Level and Age

The majority of respondents hold $\mathrm{PhDs}$ or other advanced degrees. Of the $57 \%$ of worldwide respondents who hold a $\mathrm{PhD}, 53 \%$ are female and $42 \%$ are male (5\% of respondents did not provide an answer). Only $2 \%$ of practicing zooarchaeologists did not hold higher degrees, with 13\% having at least a baccalaureate degree and $27 \%$ completing a master's. For the US and Canada, $58 \%$ of individuals had completed a $\mathrm{PhD}$, and those holding a $\mathrm{PhD}$ were $57 \%$ female and $43 \%$ male. This presents a notable shift from Gifford-
Gonzalez's 1991 results, where 68\% of PhDs among zooarchaeologists were held by men and just $32 \%$ by women in the US and Canada. Of respondents in the US and Canada, $33 \%$ of women and $20 \%$ of men are currently students-out of 28 total students, 20 were women and only 8 were men. There are also higher numbers of younger women in the profession today, particularly in their 20s and 30s, a likely reflection of the high proportions of female students. Despite the lack of men in their 50 s in the sample, there are more men in their 60s than women, individuals who were likely early to mid-career in the early 1990s. In general, the survey had a larger number of responses by younger individuals potentially caused by the higher tendency for younger respondents to participate in online surveys. This bias may be reflected in some of the degree attainment and salary data as well as a higher tendency for younger respondents to participate in online surveys.

\section{Income}

If more women are now earning $\mathrm{PhDs}$ in (zoo) archaeology as documented above, are they entering professional positions at the same rates as men and are they getting paid the same? A majority responded to this question (Figure 4, n=271) and of individuals in the lowest income bracket (earning \$0-20,000 USD per year), $70 \%$ are women and $30 \%$ are men $(n=104)$. The ratio of women to men for income brackets between $\$ 20,000-\$ 80,000$ are roughly equivalent, with slightly more women in each category, though overall numbers of individuals in these categories decreases with higher rates of pay. There are more men $(55 \%)$ than women in the third highest category $(\$ 80,000$ $100,000, n=29)$ but an equal number earning over $\$ 100,000(\mathrm{n}=14)$. Because income levels and standards may vary substantially between the many countries represented, it is difficult to interpret the significance

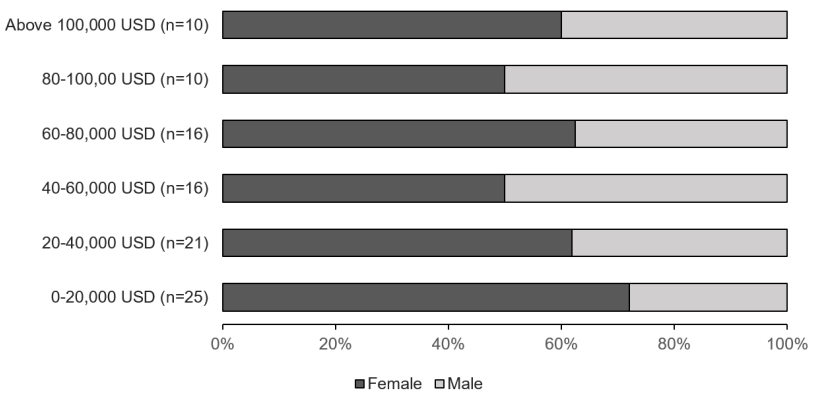

Figure 5. Percentages of men and women within each income bracket for the US and Canada ( $n=98)$. 


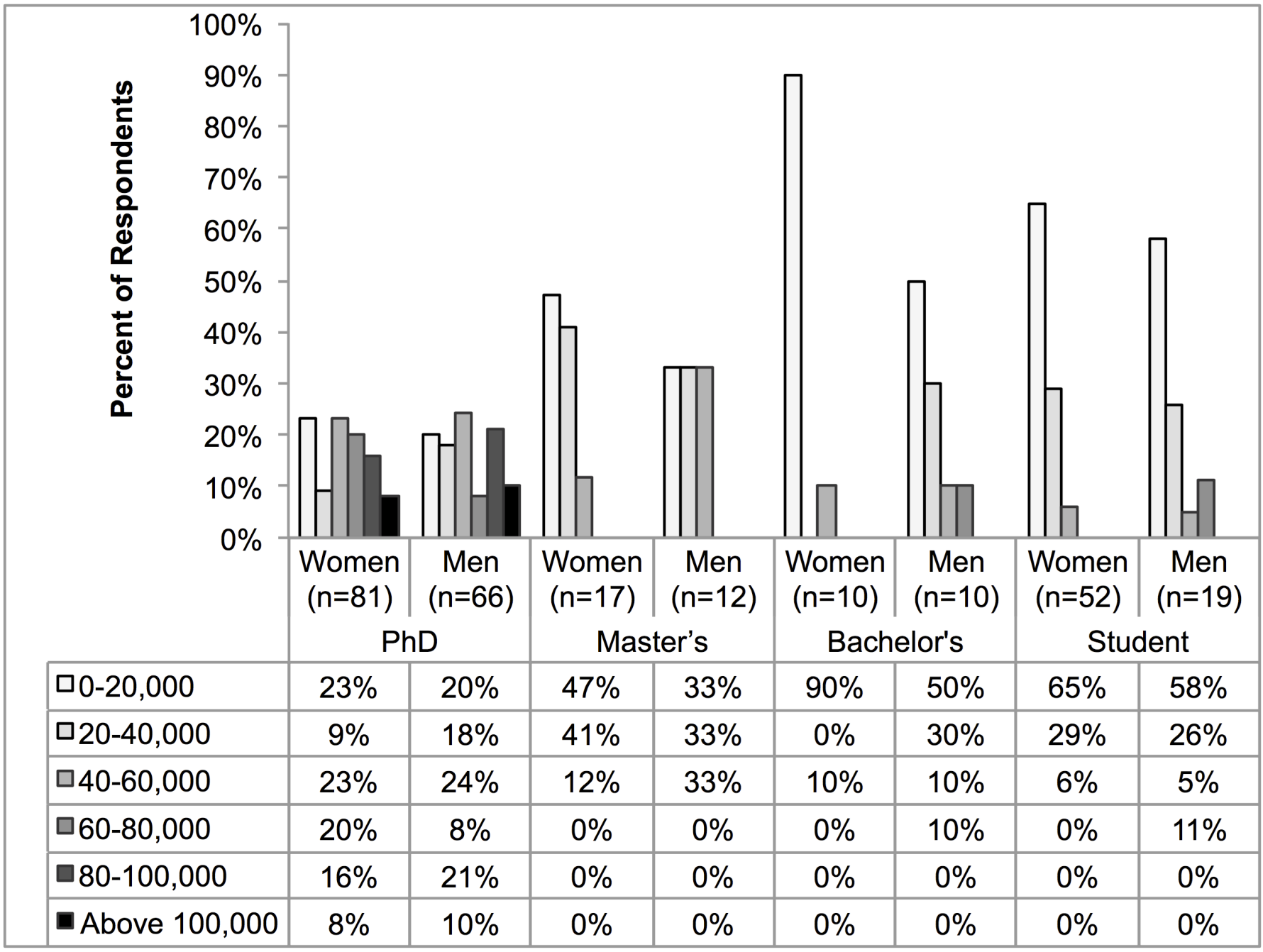

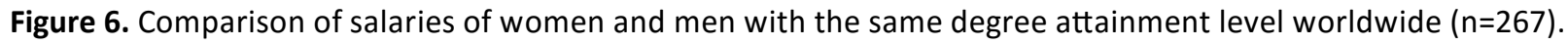

of these data as a whole. In the US in 2014, women in higher education earned an average of $21 \%$ less than men for equivalent positions (AAUW Report 2015). When data from this survey are parsed to include the US and Canada only (Figure 5, $\mathrm{n}=98$ ), there remain more women than men in the lowest income category ( $72 \%$ and $28 \%$, respectively, $n=25$ ). However, there is apparently more parity at median income levels, with an even $50 \%$ split in the $\$ 40,000-60,000(\mathrm{n}=16)$ and the $\$ 80-100,000(\mathrm{n}=10)$ income brackets. There are slightly more women at the highest income level $(60 \%, n=10)$. These data indicate that the majority of the highest earners are located in the US and Canada (10 out of 14 individuals), while the majority of the lowest earners (79 out of 104 individuals, or around $75 \%$ ) are located outside these countries.
Because the survey documents more women in the field of zooarchaeology as a whole, it is logical to expect proportionally more women in each category. The fact that the lowest income bracket has the most women is problematic. Does this discrepancy correspond with high numbers of low-paid (female) students or are women with higher degrees on average, more likely to be paid less than men for similar positions? When annual earnings are parsed by degree of education, it is possible to consider whether women and men at the same degree level earn the same. Figures 6 and 7 indicate that regardless of sex, individuals with advanced degrees earn more than those with less advanced degrees, both globally and in the US and Canada. Extrapolating these results across the discipline, there are slightly more women with $\mathrm{PhDs}$ than men in the lowest earning category, and 


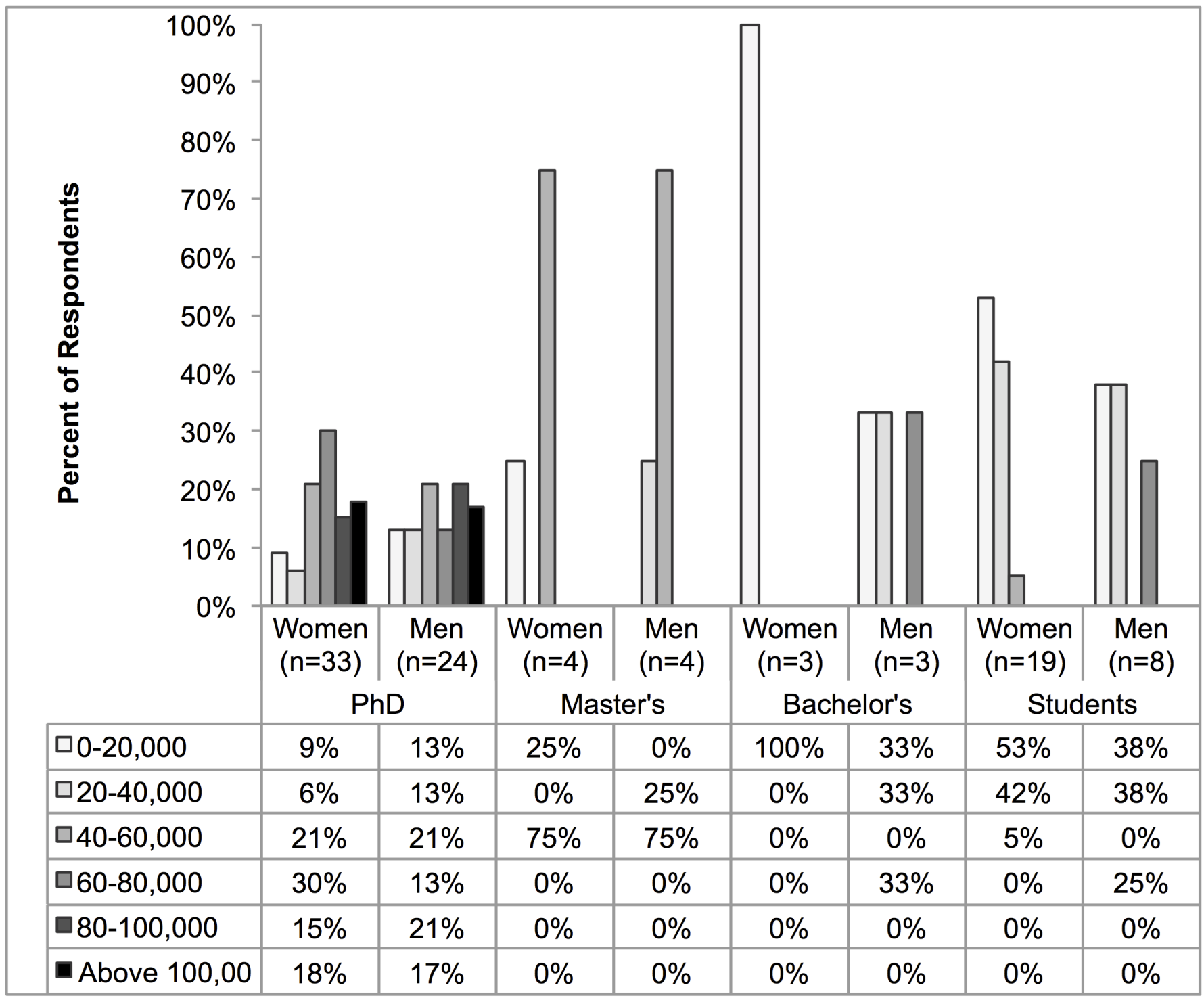

Figure 7. Comparison of salaries of women and men with the same degree attainment level in the U.S. and Canada $(n=98)$.

significantly more in the Master's, Bachelor's, and Student levels. At the median income level of $\$ 40$ 60,000 , there appears to be parity for those individuals with a $\mathrm{PhD}$, Bachelor's, and among students, but not for those with a Master's degree. There are more women with $\mathrm{PhDs}$ earning in the \$60-80,000 bracket than men. Within the bracket of $\$ 80-100,000$, however, there are still more men with $\mathrm{PhDs}$ both worldwide and the US and Canada.

Gifford-Gonzalez's 1991 survey did not ask specifically about yearly earnings, but inferred that since more men held higher ranking positions, this presumably correlated with higher salaries. The shift to increased salaries for women is likely related to demographic changes occurring throughout the 1990s and early 2000s, as female students entered professional positions. However, considering the higher numbers of women overall, there is still a disproportionately greater number of women with advanced degrees earning at the lowest income bracket. It would seem that this inequity arises not from differential payment for individuals with $\mathrm{PhDs}$, but from more unequal distribution at the lower degree levels, with men more often being paid more than women.

On the related subject of job satisfaction, 16 out of 26 written comments submitted by women further 
detailed their economic situation and touched on issues affecting their ability to conduct faunal analysis, such as childcare, lack of employment opportunities, and lack of pay, with many having to choose an alternate career path or volunteering their skills. In contrast, only two out of 19 comments written by men related a similar tone of job dissatisfaction; the majority tended to add more details about their research interests and work focus. This disparity may be a result of the a larger number of women who occupy lower-earning and freelance positions despite apparent parity at mid-income levels.

\section{Race and Ethnicity}

This survey response field did not offer a predefined set of choices in recognition of the fact that individuals of many different nationalities with different conceptions of race and ethnicity would be completing the survey. For instance, the U.S. Census uses the terms White, Black, American Indian or Alaskan Native, Asian, Native Hawaiian or Pacific Islander for race; Hispanic or Latino/a are defined as a category of ethnicity regardless of race (U.S. Census 2013). I provide a breakdown of the most common answers using the conventions of the US Census (Table 3). Responses that included White or Caucasian are tallied together here as "White" (55\%). A large percentage of Europeans repeated their country of origin for the race/ethnicity category or stated "European" (19\%). Very few people identified as Asian $(2 \%)$ and Latino/a regardless of country of citizenship (1\%). No individuals self-identified as African-American or Black, American Indian or Alaskan Native, or Native Hawaiian or Pacific Islander. Three individuals identified as having mixed Asian-American heritage. In addition to not providing answers $(18 \%)$, a small number of respondents $(4 \%)$ took umbrage at the question, making statements like "I don't believe in this" and "Really? Sorry, I thought an anthropologist was doing this survey" or wrote "Homo sapiens" or "human;" one response included "Neanderthal."

Race and ethnicity are social constructs, they matter and have real-life implications for millions of people who are systemically or individually discriminated against every day. To deny the existence of these socially constructed categories is a privilege in itself. It is relevant to consider the racial and ethnic diversity of zooarchaeologists as a group because such self-identification likely influences practices and perceptions in the field.
Table 3. Self-identified race and ethnicity among zooarchaeologists.

\begin{tabular}{lrr}
\hline Race/Ethnicity & All & $\begin{array}{r}\text { US and } \\
\text { Canada }\end{array}$ \\
\hline European Descent, no further & 56 & 0 \\
information & 157 & 85 \\
White & 5 & 3 \\
Asian and Pacific Islander & 4 & 0 \\
Latino/a & 52 & 9 \\
No Answer & 14 & 3 \\
Other & & \\
\hline
\end{tabular}

\section{Discussion and Conclusion}

Opening the survey to global participation means that there are different norms across countries to be considered, but there are a number of trends in the data that can be compared with Gifford-Gonzalez's previous survey as well as the data from the Society for American Archaeology in 1994 and 2004 (Zeder 1997, Association Research 2005). It now does seem that a majority of the "bone people" are women; at least in US and Canada, while there are still larger proportions of female students and women tend to be younger than men, the comparison of salary levels suggest that the situation has improved substantially over the last 20 years.

Though the number of countries represented in the current survey is exciting, the comparatively low representation of the global south in general is problematic, as is the underrepresentation of zooarchaeologists who are residents of certain regions of high research activity (e.g., Southwest Asia). ICAZ does support the development of local communities of zooarchaeologists in currently less well represented regions, and there are some discrepancies in geographic representation between the survey and ICAZ membership data as noted above and in Table 1. Though difficult to gauge across international borders due to differences in historical circumstance and population numbers, the general lack of racial and ethnic diversity in zooarchaeology, particularly in the US and Canada sample, is also troubling. Though zooarchaeologists have tended to focus less on the study of animal remains from historic periods, the growth of interest in human-animal studies within the humanities presents an intellectual opportunity that should not be overlooked. Finally, while the online format of the survey made it accessible, with a higher response rate than the 1991 survey and an internation- 
al scope, this work should not be considered exhaustive nor all-inclusive. Rather, it should stand as part of an ongoing conversation about equity, representation, and inclusivity within and beyond the discipline of zooarchaeology.

\section{Acknowledgements}

I would like to thank Diane Gifford-Gonzalez for providing the original survey questions along with a copy of her initial report in Zooarchaeology Research News. Sarah Whitcher Kansa and Iain McKechnie provided valuable feedback on this manuscript, as did two anonymous reviewers, for which I am grateful. Finally, I would also like to thank all those in the zooarchaeology community who responded and made this a successful survey.

\section{Declarations}

Permissions: An Institutional Review Board exemption for this research was granted by the Brown University Research Protections Office (\#1309000919).

Sources of Funding: Survey results were presented as a poster at the 2014 conference of the International Council for Archaeozoology with financial support from the Foreign Travel Assistance Program Grant, Office of the Vice President for Research, University of Georgia.

Conflicts of Interest: None declared.

\section{References}

Aitchison, K., and D. Rocks-Macqueen. 2013. Archaeology Labour Market Intelligence: Profiling the Profession 2012-13. Landward Research. Available at: http://www.landward.eu/2013/10/archaeologylabour-market-intelligence-profiling-the-profession2012-13.html.

American Association of University Women (AAUW). 2015. The Simple Truth about the Gender Pay Gap. American Association of University Women. Available at: http://www.aauw.org/resource/thesimple-truth-about-the-gender-pay-gap/.

American Anthropological Association. 2015. 20152016 AnthroGuide. Available at: http:// new.aaanet.org/publications/guide.cfm.

Association Research, Inc. 2005. 2005 Salary Survey. Society for American Archaeology. Available at:
http://www.saa.org/Careers/2005SalarySurvey/ tabid/253/Default.aspx.

Gero, J. M. 1985. Socio-Politics and the Woman-atHome Ideology. American Antiquity 50:342-350.

Gifford-Gonzalez, D. 1993. Report on the Zooarchaeology Practitioner Survey. Zooarchaeology Research News 12:3-15.

Gifford-Gonzalez, D. 1994. Women in Zooarchaeology. Archeological Papers of the American Anthropological Association 5:155-171.

Lazar, I., T. Kompare, H. van Londen, and T. Schenk. 2014. The Archaeologist of the Future is Likely to be a Woman: Age and Gender Patterns in European Archaeology. Archaeologies 10:257-280.

National Science Foundation. 2015. Survey of Earned Doctorates. Available at: https://ncses.norc.org/ NSFTabEngine/\#WELCOME.

Ulm, S., S. Nichols, and C. Dalley. 2005. Mapping the Shape of Contemporary Australian Archaeology: Implications for Archaeology Teaching and Learning. Australian Archaeology 61:11-23.

U.S. Census Bureau. 2013. Race. Available at: http:// www.census.gov/topics/population/race/ about.html.

Zeder, M. 1997. The American Archaeologist: A Profile. AltaMira Press, Walnut Creek. CA.

\section{Notes}

${ }^{1}$ Zooarchaeology Research News was an independent quarterly print newsletter edited and published by Pam Crabtree and Doug Campana between 1987 and 1994.

${ }^{2}$ The $A A A$ Guide to Departments of Anthropology was published by the American Anthropological Association beginning in 1962 and was titled The $A A A$ Guide between 1989-2010. It is now available online and in print as the AnthroGuide.

\section{Biosketch}

Suzanne E. Pilaar Birch is joint assistant professor in the Departments of Anthropology and Geography and directs the Quaternary Isotope Paleoecology Laboratory at University of Georgia. 